\title{
Wire-over-wire technique enables placement of a second parallel guidewire into a pseudocyst for drainage
}

Recently we reported a new technique that enables the positioning of a second guidewire following a first wire without the use of a catheter [1]. Using a wire with a double-bend tip, which forms the shape of a helix, it is possible to wrap the new wire around a first guidewire and advance it. We have already successfully demonstrated this technique in biliary interventions [1]. In the following, we present the case of a patient with a symptomatic pancreatic fluid collection, in whom we used this technique to pass a second wire into the pseudocyst to allow drainage with two double-pigtail stents.

First, we punctured the pseudocyst through the gastric wall using a $19 \mathrm{G}$ needle (Cook Medical, Winston-Salem, North Carolina, USA). A 0.035-inch guidewire (JagWire; Boston Scientific, Natick, Massachusetts, USA) was then inserted through this needle. The guidewire was used to guide a 6 -Fr cystotome into the pseudocyst to form a tract.

The procedure was switched from endoscopic ultrasound to endoscopic view. With the 6-Fr cystotome positioned beside the guidewire, a second wire with a double bend (Smart Wire, MTW Endoskopie, Wesel, Germany) was wrapped around the first wire and then advanced, thereby following the first wire into the pseudocyst. Both wires were again separated from each other using counterclockwise rotation ( $\triangleright$ Video 1 ). A 7-Fr double-pigtail stent (11-cm long) was inserted over each wire, and a good flow of pseudocyst fluid was seen endoscopically.

This case demonstrates for the first time the feasibility of inserting a second wire into a pseudocyst without using a catheter or other device. Cannulation of a pseudocyst using a catheter with a wire alongside another wire can sometimes be challenging or unsuccessful because

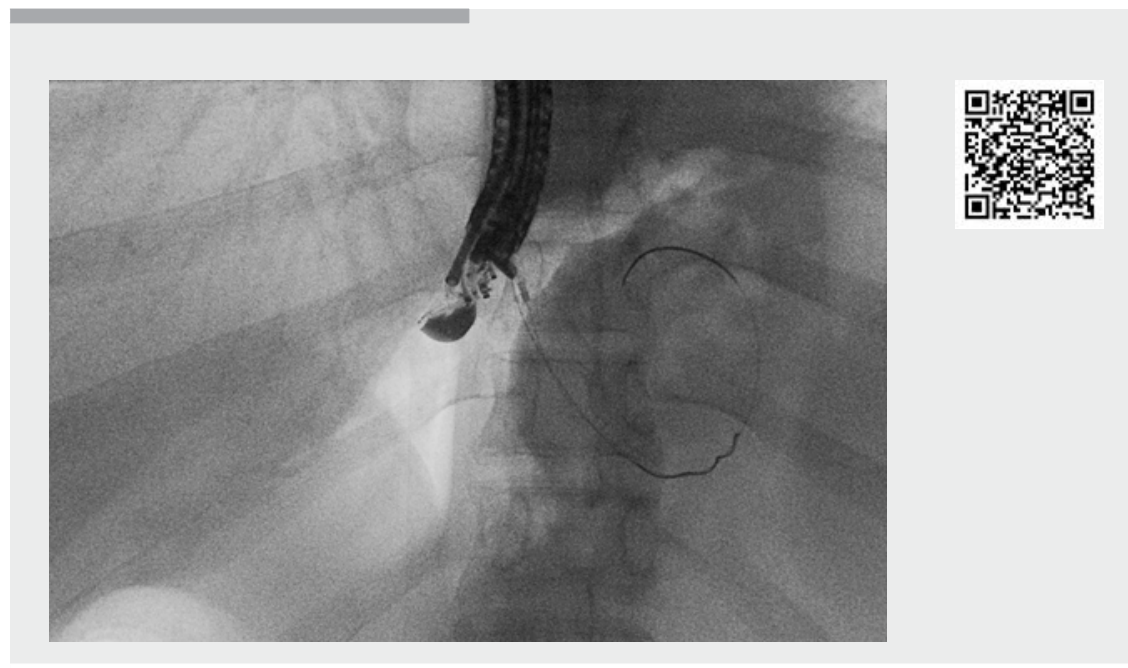

Video 1 The video demonstrates the application of the wire-over-wire technique to insert two parallel guidewires into a pseudocyst. After the initial puncture, a straight guidewire is inserted and a 6-Fr cystotome is used to form a tract into the cyst. The Smart Wire is then wrapped around the first guidewire by clockwise rotation. After the second wire has been advanced, the two wires are separated using counterclockwise rotation.

it is only possible if the cannulation can be performed in parallel to the axis of the first wire, which is sometimes hard. Use of the Smart Wire allows the axis of the first wire to be followed automatically and the exact positioning is of little importance.

Owing to the simplicity of the technique, the wire-over-wire technique may be able to replace other techniques that have been invented for the placement of two wires into a pseudocyst, such as double cannulation through larger diameter catheters [2,3] or other complicated techniques. In addition, no extra material is needed to perform the second wire cannulation. In conclusion, we advocate the use the wire-over-wire technique for the placement of more than one wire into a pancreatic fluid collection.

Endoscopy_UCTN_Code_TTT_1AS_2AD

\section{Competing interests}

J. Weigt receives procedural payments for licence business from the patent holder, the University of Magdeburg.

The authors

Jochen Weigt, Wilfried Obst, Ali E. Canbay Department of Gastroenterology Hepatology and Infectious Diseases, Otto-v.-Guericke University of Magdeburg, Magdeburg, Germany

\section{Corresponding author}

\section{Jochen Weigt, MD}

Dept. Gastroenterology Hepatology and Infectious Diseases, Otto-v.-Guericke University of Magdeburg, Leipziger Str. 44, 39120 Magdeburg, Germany Fax: +49-391-6713105

Jochen.weigt@med.ovgu.de 
Bibliography

[1] Weigt J, Obst W, Canbay A. Wire-over-wire technique. Endoscopy 2019; 51: E137

[2] Binmoeller KF, Weilert F, Shah JN et al. Endosonography-guided transmural drainage of pancreatic pseudocysts using an exchange-free access device: initial clinical experience. Surg Endosc 2013; 27: 1835 1839

[3] Seewald S, Thonke F, Ang T-L et al. One-step, simultaneous double-wire technique facilitates pancreatic pseudocyst and abscess drainage (with videos). Gastrointest Endosc 2006; 64: 805-808
DOI https://doi.org/10.1055/a-0986-3139

Published online: 16.10 .2019

Endoscopy 2020; 52: E114-E115

(c) Georg Thieme Verlag KG

Stuttgart · New York

ISSN 0013-726X

\section{ENDOSCOPY E-VIDEOS}

https://eref.thieme.de/e-videos

口回 Endoscopy E-Videos is a free 登视 自: on interesting cases and new techniques in gastroenterological endoscopy. All papers include a high quality video and all contributions are freely accessible online.

This section has its own submission website at

https://mc.manuscriptcentral.com/e-videos 